\title{
Características da Carcaça de Bovinos de Quatro Grupos Genéticos Submetidos a Dietas com ou sem Adição de Gordura Protegida ${ }^{1}$
}

\author{
Soraya Maria Palma Luz Jaeger ${ }^{2}$, Alecssandro Regal Dutra ${ }^{3}$, José Carlos Pereira ${ }^{4}$, Ivy Scorzzi \\ Cazelli de Oliveira ${ }^{5}$
}

RESUMO - Com o objetivo de avaliar o rendimento e as características de carcaça de quatro grupos genéticos de bovinos, foram abatidos 32 animais machos inteiros, dos grupos Nelore (N), $\mathrm{F}_{1}$ Canchim x Nelore (CN), $\mathrm{F}_{1}$ Limousin $\mathrm{x}$ Nelore (LN) e $\mathrm{F}_{1}$ Aberdeen Angus x Nelore (AN), com idade aproximada de 19 meses e peso vivo médio de $558 \mathrm{~kg}$, terminados em regime de confinamento, recebendo dietas com ou sem adição de gordura protegida, durante 166 dias. O delineamento experimental utilizado foi inteiramente casualizado, com quatro repetições, seguindo esquema fatorial 2 x 4 (dieta, grupo genético). Observou-se efeito do grupo genético sobre o rendimento de cortes primários, tendo o grupo AN apresentado as maiores médias de dianteiro (41,65\%) e ponta de agulha (13.90\%) e o grupo LN, o maior rendimento de traseiro (47,40\%). A área de olho de lombo (AOL) sofreu efeito da dieta, apresentando médias de $81,31 \mathrm{~cm}^{2} v s .88,50 \mathrm{~cm}^{2}$, para as dietas sem e com gordura protegida, respectivamente. A composição física da carcaça foi influenciada pelo grupo genético, tendo o grupo LN apresentado a maior porcentagem de músculo (63,62\%) e a menor porcentagem de tecido adiposo (21,65\%), enquanto o grupo Nelore apresentou a maior porcentagem de tecido adiposo $(28,28 \%)$ e menor porcentagem de músculo (56,76\%). A composição química da seção HH sofreu efeito do grupo genético, tendo sido observados os maiores teores de proteína bruta nos grupos LN (27,24\%) e CN (26,10\%) e de extrato etéreo no grupo Nelore (68,35\%), que não diferiu do grupo $\mathrm{AN}(68,02 \%)$. Os menores teores de $\mathrm{Ca}, \mathrm{P}$ e $\mathrm{Mg}(2,62$; 1,32 ; e $0,081 \%$ ) foram observados no grupo Nelore.

Palavras-chave: composição da carcaça, gordura encapsulada, mestiços Europeu x Zebu

\section{Carcass Characteristics of Bovines from Four Genetic Groups Fed Diets with or without Protected Fat}

\begin{abstract}
The objective of this experiment was to evaluate the yield and carcass characteristics of steers from the following four genetic group: Nellore (N), F1 Canchim x Nellore (CN), F1 Limousin x Nellore (LN) and F1 Aberdeen Angus x Nellore (NA). For this purpose, 32 steers, with age of 19 months and live weight average of $558 \mathrm{~kg}$, raised in confinement and fed diet with and without protected fat for 166 days, were slaughtered. A completely randomized design, with four replicates, following a factorial scheme of 2 x 4 (diet, genetic group), was used. The effect of genetic group was observed on the prime cuts yield and the group NA presented the greatest yield means of the hindquarter (41.65\%) and spare ribs (13.90\%) and the group LN presented a greater yield of forequarter $(47.40 \%)$. The loin eye area (AOL) was affected by the diet, showing means of $81.31 \mathrm{~cm}^{2} \mathrm{vs.} 88.50 \mathrm{~cm}^{2}$ in the diets without and with protected fat, respectively. The physical composition of the carcass was affected by the genetic group, and the group LN showed the greatest percentage of muscle $(63.62 \%)$ and the lowest percentage of fat tissue $(21.65 \%)$, while the group Nellore showed the greatest percentage of fat tissue (28.28\%) and the lowest percentage of muscle (56.76\%). The chemical composition of the HH section was affected by the genetic group, and the greatest contents of crude protein were observed in the groups $\mathrm{LN}(27.24 \%)$ and $\mathrm{CN}(26.10 \%)$, and the ether extract in the group Nellore (68.35\%), that did not differ form the AN (68.02\%). The lowest contents of Ca, P and Mg (2.62; 1.32 and $0.081 \%$ ) were observed in the group Nellore.
\end{abstract}

Key Words: carcass composition, by pass fat, European x Zebu crossbred

\section{Introdução}

O Brasil apresenta um dos maiores efetivos bovinos do globo, constituído por aproximadamente 160 milhões de cabeças (Esteves, 1998), das quais 74,5\% são animais de corte e 4\%, de aptidão mista (Corrêa, 2000). Entretanto, apesar do considerável incremento dos índices de produtividade e do expressivo aumento das exportações observado no setor da pecuária de corte nos últimos anos, o volume das exportações

\footnotetext{
1 Parte da tese apresentada à UFV, pelo primeiro autor, para obtenção do título de Doutor em Zootecnia.

2 Professor do Departamento de Zootecnia da Escola de Agronomia da UFBA (sljaeger@ufba.br).

3 Professor da UCG, Goiânia, GO.

4 Professor do DZO/Universidade Federal de Viçosa, Bolsista do CNPq

5 Doutora em Nutrição - DPN/ UFV.
} 
destes produtos continua aquém do potencial que pode ser atingido.

As principais causas relacionadas à falta de competitividade da carne bovina brasileira no mercado externo são basicamente: a baixa produtividade do rebanho nacional, a falta de incentivo aos produtores na forma de remuneração diferenciada, de acordo com a qualidade do produto comercializado, a má qualidade sanitária da carne, em razão da alta incidência de zoonoses, e as dificuldades encontradas para implantação de um programa de rastreabilidade, atualmente exigido por muitos mercados importadores (Corrêa, 2000).

Apenas as mudanças estruturais na pecuária de corte, baseadas na concepção de produção que começa a se estabelecer no setor agroindustrial brasileiro, onde a qualidade, o rendimento e a composição da carcaça são indispensáveis, seriam capazes de fornecer condições para que a carne bovina brasileira se tornasse competitiva em um mercado internacional crescente e cada vez mais exigente (Corrêa, 2000). Estas mudanças incluem a adoção de sistemas de cruzamento bem orientados que possibilitem, simultaneamente, otimizar os efeitos não aditivos (heterose) e os efeitos aditivos dos genes sobre as características de carcaça com a escolha de raças que se complementem.

Cruzamentos entre raças zebuínas e européias têm proporcionado à pecuária de corte nacional os benefícios do chamado vigor híbrido, incrementando a produtividade do rebanho e promovendo o aumento do rendimento de carcaça, a produção de animais com crescimento rápido e eficiente, com boa cobertura muscular e carcaças de melhor qualidade (Arruda, 1994). Estes cruzamentos originam animais melhorados com elevadas exigências nutricionais que necessitam de dietas com alta densidade energética para que alcancem o peso e a carcaça ideal, com a quantidade mínima de gordura de cobertura, no menor tempo possível (Lanna, 1997; Restle, 1997).

$\mathrm{O}$ aumento da densidade energética da ração, obtido pela suplementação com gordura, mantendose adequada relação volumoso:concentrado, é uma estratégia nutricional que pode ser utilizada na engorda de bovinos de elevado padrão genético em confinamento (Church, 1984), com a vantagem de não apresentar os inconvenientes distúrbios metabólicos digestivos, causados por dietas de alta densidade energética à base de grãos, ricas em carboidratos prontamente fermentescíveis.
Entretanto, as evidências de que a adição de gordura (principalmente a insaturada) possa ter efeito negativo sobre a fermentação ruminal, interferindo negativamente sobre a digestibilidade da fibra (Demeyer \& Doreau, 1999), parecem limitar a aplicação desta prática.

Ainda assim, observa-se crescente interesse pela utilização de suplementação lipídica como fonte de energia nas rações de ruminantes, o que tem estimulado o desenvolvimento de pesquisas com ampla variedade de fontes de gordura, buscando, principalmente, conhecer seus efeitos sobre a fermentação ruminal (Jenkins, 1993) e a redução dos teores de gordura saturada na carne e no leite (Maloney et al., 2001). Estas pesquisas têm apontado os ácidos graxos complexados com cálcio, também chamados de gordura protegida, como a fonte lipídica, que tem apresentado os melhores resultados quanto a estes aspectos e, por isso, tem sido bastante recomendada (Jenkins, 1993).

Embora o uso de gordura protegida seria indicado atualmente como alternativa potencialmente viável para a engorda de bovinos de elevado padrão genético em confinamento, continuam escassos os trabalhos científicos que avaliam os efeitos desta prática sobre o rendimento e as características de carcaça.

Objetivou-se, com o presente estudo, a avaliação do rendimento e das características de carcaça de bovinos de quatro grupos genéticos (Nelore, $F_{1}$ Canchim $\mathrm{x}$ Nelore, $\mathrm{F}_{1}$ Limousin $\mathrm{x}$ Nelore $\mathrm{e} \mathrm{F}_{1}$ Aberdeen Angus x Nelore) submetidos a dietas com ou sem adição de gordura vegetal complexada com sais de cálcio.

\section{Material e Métodos}

Foram utilizados 32 bovinos machos inteiros, de quatro grupos genéticos, a saber: Nelore $(\mathrm{N}), \mathrm{F}_{1}$ Canchim x Nelore $(\mathrm{CN}), \mathrm{F}_{1}$ Limousin $\mathrm{x}$ Nelore (LN) e $F_{1}$ Aberdeen Angus x Nelore (AN), previamente marcados, desverminados e suplementados com vitaminas $\mathrm{A}, \mathrm{D}$ e $\mathrm{E}$ (via intramuscular), com idade inicial de 14 meses e peso vivo inicial médio de $358 \mathrm{~kg}$, respectivamente.

Os tratamentos experimentais consistiram dos quatro grupos genéticos supracitados, duas dietas isocalóricas (sem e com adição de gordura protegida), durante um período de 166 dias, compreendido entre o início do confinamento e o dia do abate. 
Ambas as dietas tiveram densidade energética calculada com base no NRC (1996), visando atender às exigências nutricionais dos animais para ganho de peso estimado em $1,5 \mathrm{~kg} / \mathrm{dia}$ e relação volumoso:concentrado equivalente a 40:60, e foram fornecidas na forma de mistura completa, com o sal mineral disponibilizado, indistintamente, a todos os animais, em cocho separado.

As proporções dos ingredientes das dietas e a composição bromatológica dos alimentos e das dietas usadas no experimento encontram-se descritas nas Tabelas 1, 2 e 3.

$\mathrm{O}$ abate dos animais, realizado 166 dias após o início do experimento nas instalações do frigorífico MINERVA, em Barretos, SP, foi precedido de período de jejum de sólidos (24 horas), seguindo o fluxo operacional próprio do frigorífico. Após o abate, foram pesadas as duas meia-carcaças de cada animal, para o cálculo do rendimento, obtido pela razão entre o peso da carcaça total e o peso vivo ao abate. As carcaças foram, então, armazenadas em câmara fria a $-5^{\circ} \mathrm{C}$, durante 24 horas e, após este resfriamento, procederam-se às medições de $\mathrm{pH}$ e temperatura,
Tabela 2 - Médias dos teores de matéria seca (MS), proteína bruta (PB), fibra em detergente neutro (FDN), extrato etéreo (EE) e matéria mineral (MM) dos alimentos utilizados nas dietas experimentais

Table 2 - Average contents of dry matter (DM), crude protein $(C P)$, neutral detergent fiber (NDF), ether extract $(E E)$ and ash of the feedstuffs used in the experimental diets

\begin{tabular}{|c|c|c|c|c|c|}
\hline \multirow[t]{2}{*}{$\begin{array}{l}\text { Alimento } \\
\text { Feedstuff }\end{array}$} & \multirow[t]{2}{*}{$\begin{array}{l}\mathrm{MS}(\%) \\
D M(\%)\end{array}$} & \multicolumn{4}{|c|}{$\begin{array}{c}\text { Dados, em } \%, \\
\text { da matéria seca } \\
\text { Data in } \% \text { dry matter }\end{array}$} \\
\hline & & $\begin{array}{l}\mathrm{PB} \\
C P\end{array}$ & $\begin{array}{l}\text { FDN } \\
N D F\end{array}$ & $\begin{array}{l}\mathrm{EE} \\
E E\end{array}$ & $\begin{array}{l}\mathrm{MM} \\
M M\end{array}$ \\
\hline $\begin{array}{l}\text { Feno de Brachiaria } \\
\text { Brachiaria decumbens } \\
\text { decumbens }\end{array}$ & $\begin{array}{l}92,29 \\
\text { hay }\end{array}$ & 4,48 & 70,04 & 0,68 & 6,34 \\
\hline $\begin{array}{l}\text { Farelo de soja } \\
\text { Soybean meal }\end{array}$ & 88,74 & 47,44 & 14,83 & 1,57 & 6,26 \\
\hline $\begin{array}{l}\text { Milho (grão moído) } \\
\text { Ground corn }\end{array}$ & 87,64 & 9,05 & 11,61 & 4,01 & 1,44 \\
\hline $\begin{array}{l}\text { Melaço em pó } \\
\text { Molasses }\end{array}$ & 95,00 & 2,00 & - & - & 20,0 \\
\hline $\begin{array}{l}\text { Gordura protegida }{ }^{1} \\
\text { Protected fat }\end{array}$ & 95,00 & - & - & 82,0 & 18,0 \\
\hline
\end{tabular}

1 Produto comercial ( LAC 100 - Yakult @) à base de óleo de soja complexado com cálcio.

1 Soybean oil plus calcium commercial product (LAC $100-$ Yakult).
Tabela 1 - Composição percentual das dietas fornecidas aos animais experimentais (\% MS)

Table 1 - Percent composition of the diets fed to the experimental animals (\%DM)

\begin{tabular}{|c|c|c|}
\hline \multirow[b]{2}{*}{$\begin{array}{l}\text { Ingrediente } \\
\text { Feedstuff }\end{array}$} & \multicolumn{2}{|l|}{$\begin{array}{l}\text { Dieta } \\
\text { Diet }\end{array}$} \\
\hline & $\begin{array}{c}\text { Sem gordura } \\
\text { protegida } \\
\text { Without protected } \\
\text { fat }\end{array}$ & $\begin{array}{l}\text { Com gordura } \\
\text { protegida } \\
\text { With protected } \\
\text { fat }\end{array}$ \\
\hline & \multicolumn{2}{|c|}{$\%$} \\
\hline $\begin{array}{l}\text { Feno de Brachiaria } \\
\text { decumbens } \\
\text { Brachiaria decumbens hay }\end{array}$ & 40,00 & 40,00 \\
\hline $\begin{array}{l}\text { Farelo de soja } \\
\text { Soybean meal }\end{array}$ & 6,30 & 12,10 \\
\hline $\begin{array}{l}\text { Milho } \\
\text { Corn }\end{array}$ & 50,70 & 39,90 \\
\hline $\begin{array}{l}\text { Melaço em pó } \\
\text { Molasses }\end{array}$ & 3,00 & 3,00 \\
\hline $\begin{array}{l}\text { Gordura protegida }{ }^{1} \\
\text { Protected fat }\end{array}$ & - & 5,00 \\
\hline
\end{tabular}

R. Bras. Zootec., v.33, n.6, p.1876-1887, 2004 (Supl. 1)
Tabela 3 - Médias dos teores de matéria seca (MS), proteína bruta (PB), fibra em detergente neutro (FDN), carboidratos totais (CHOT), nutrientes digestíveis totais (NDT), extrato etéreo (EE) e matéria mineral (MM) das dietas experimentais

Table 3 - Average contents of dry matter (DM), crude protein $(C P)$, neutral detergent fiber (NDF), total carbohydrates (TC), total digestible nutrients $(T D N)$, ether extract $(E E)$ and ash of the experimental diets

\begin{tabular}{|c|c|c|c|c|c|c|}
\hline \multirow[t]{2}{*}{$\begin{array}{l}\text { Alimento } \\
\text { Feedstuffs }\end{array}$} & \multirow[t]{2}{*}{$\begin{array}{l}\text { MS (\%) } \\
D M(\%)\end{array}$} & \multicolumn{5}{|c|}{$\begin{array}{c}\text { Dados em } \% \\
\text { da matéria seca } \\
\text { Data in } \% \text { dry matter }\end{array}$} \\
\hline & & PB & FDN & CHOT & $\mathrm{NDT}^{1} \mathrm{EE}$ & MM \\
\hline $\begin{array}{l}\text { Sem GP }{ }^{2} \\
\text { Without PF }\end{array}$ & 89,8 & 9,50 & 34,84 & 83,84 & $72,4 \quad 2,40$ & 4,26 \\
\hline $\begin{array}{l}\text { Com GP } 2 \\
\text { With PF }\end{array}$ & 90,2 & 11,0 & 34,44 & 77,51 & $72,8 \quad 6,16$ & 5,33 \\
\hline
\end{tabular}

1 Determinado por meio de ensaio de digestibilidade, considerando-se: NDT = PBD+CHOTD+ EED x 2,25 (Sniffen et al., 1992) (Determined by means of the digestibility trial, considering TDN = $D C P+D C H O T+D E E \times 2.25$ [Sniffen et al., 1992]).

$2 \mathrm{GP}=$ Gordura protegida (Protected fat). 
com medidor eletrônico, nas regiões do contra-filé e do coxão mole.

Cada meia-carcaça direita foi inicialmente dividida em cortes primários: dianteiro, ponta de agulha e traseiro especial. Em seguida, foram obtidos os cortes comerciais (padrão brasileiro) resultantes da desossa do traseiro: alcatra, coxão-duro, coxão-mole, contrafilé, filé-mignon, lagarto, capa e aba de contra-filé, músculo e patinho. Tanto os cortes primários como os cortes comerciais tiveram seus rendimentos expressos em porcentagem da meia-carcaça.

Das meia-carcaças esquerdas, foram coletadas amostras correspondentes à seção da $9 \underline{a}$ à $11^{\mathrm{a}}$ costelas (seção $\mathrm{HH}$ ), segundo metodologia descrita por Hankins \& Howe (1946), e, à altura da 12a segunda costela, foram medidas a espessura da gordura de cobertura (utilizando-se um paquímetro) e a área de olho do músculo Longissimus dorsi (área de olho de lombo), usando a metodologia do quadrante de pontos descrita pelo "USDA yield grade" (1989), citada por Burson (1997).

Todas as seções $\mathrm{HH}$ foram dissecadas, para posterior predição das proporções de músculo, tecido adiposo e ossos na carcaça, segundo equações preconizadas por Hankins \& Howe (1946):

Proporção de músculo: $\quad \mathrm{Y}=16,08+0,80 \mathrm{X}$ Proporção de tecido adiposo: $\mathrm{Y}=3,54+0,80 \mathrm{X}$ Proporção de ossos: $\quad \mathrm{Y}=5,52+0,57 \mathrm{X}$

em que: $\mathrm{X}=$ porcentagem do componente na seção $\mathrm{HH}$.

Após a dissecação, foram coletadas amostras compostas (osso, músculo e gordura), representativas de cada seção $\mathrm{HH}$ (pesando $500 \mathrm{~g}$ e guardando a mesma proporção de componentes das respectivas seções), para determinação dos teores de matéria seca gordurosa e de matéria seca pré-desengordurada, conforme descrito por Kock \& Preston (1979).

As amostras compostas (secas e desengorduradas) de cada seção HH foram trituradas em moinho de bola e armazenadas em frascos de vidro com tampa, para posteriores análises de proteína bruta, pelo método semi-micro Kjeldhal (AOAC, 1984); de extrato etéreo, usando extrator "Goldfish"; e de cinzas, em mufla elétrica a $600^{\circ} \mathrm{C}$, conforme metodologia descrita por Silva (1998).

As determinações dos teores de cálcio $(\mathrm{Ca})$, fósforo $(\mathrm{P})$, magnésio $(\mathrm{Mg})$, potássio $(\mathrm{K})$ e sódio (Na) das amostras compostas das seções HH foram feitas com auxílio de soluções minerais preparadas por via úmida, e devidamente diluídas, segundo metodologia apresentada por Silva (1998). O teor de fósforo determinado por colorimetria; os teores de cálcio e de magnésio, em espectrofotômetro de absorção atômica; e os teores de sódio e de potássio, em espectrofotômetro de chama.

$\mathrm{O}$ delineamento experimental empregado foi inteiramente casualizado, com quatro repetições, seguindo um esquema fatorial $2 \times 4$ (duas dietas e quatro grupos genéticos).

As variáveis avaliadas foram analisadas segundo o modelo matemático:

$$
\mathrm{Y}_{\mathrm{jik}}=\mu+\mathrm{D}_{\mathrm{i}}+\mathrm{G}_{\mathrm{j}}+\mathrm{DG}_{\mathrm{ij}}+\mathrm{e}_{\mathrm{jik}}
$$

em que $Y_{j i k}=$ observação relativa à ao k-ésimo animal, do j-ésimo grupo genético, recebendo a i-ésima dieta; $\mu=$ constante inerente ao modelo; $D_{i}=$ efeito da i-ésima dieta, $i=$ sem e com gordura protegida; $\mathrm{G}_{\mathrm{j}}=$ efeito do j-ésimo grupo genético, $\mathrm{j}=\mathrm{N}, \mathrm{CN}, \mathrm{LN}, \mathrm{e} \mathrm{AN}$; $\mathrm{DG}_{\mathrm{ij}}=$ efeito da interação da i-ésima dieta com o j-ésimo grupo genético; $\mathrm{e}_{\mathrm{jik}}=$ erro aleatório, associado a cada observação, suposto normal e independentemente distribuído, com média zero e variância $\sigma^{2}$.

Os dados obtidos foram submetidos a análises de variância e as médias, comparadas pelo teste Tukey, a 5\% de significância, utilizando o Sistema para Análises Estatísticas e Genéticas - SAEG (UFV, 1999).

\section{Resultados e Discussão}

Não houve efeito significativo da interação dieta $\mathrm{x}$ grupo genético, tampouco efeitos isolados destes parâmetros sobre as variáveis peso vivo ao abate, peso da carcaça total quente, peso da carcaça direita fria e perdas por resfriamento (Tabelas 4 e 5).

A ausência de efeito significativo do grupo genético sobre o rendimento de carcaça foi relatada por Euclides Filho et al. (1997), em estudo conduzido com animais Nelore e seus mestiços com Charolês, Fleckvieh e Chianina, e por Dutra (2000), em animais Nelore e seus mestiços com Aberdeen Angus, PardoSuíço e Simental, submetidos a dietas com diferentes níveis de concentrado.

Segundo Euclides Filho et al. (1997), as diferenças para rendimento de carcaça entre grupos genéticos, geralmente, são evidenciadas quando a data do abate é determinada pelo grau de acabamento da carcaça.

R. Bras. Zootec., v.33, n.6, p.1876-1887, 2004 (Supl. 1) 
Tabela 4 - Médias do peso vivo ao abate (PVA), peso de carcaça total quente (CTQ), rendimento de carcaça (RC), peso da carcaça direita quente (CDQ), peso da carcaça direita fria (CDF) e perdas por resfriamento (PR), em função dos grupos genéticos

Table 4 - Means of live weight at slaughter (LWS), hot total carcass weight (HTC), carcass dressing (CD), hot right carcass weight $(H R C)$, cold right carcass weight $(C R C)$ and cooling losses $(C L)$, according to the genetic groups

\begin{tabular}{lcccccc}
\hline $\begin{array}{l}\text { Grupo genético } \\
\text { Genetic group }\end{array}$ & \multicolumn{5}{c}{$\begin{array}{c}\text { Parâmetro } \\
\end{array}$} & Parameter \\
\cline { 2 - 7 } & PVA & CTQ & RC & CDQ & CDF & PR \\
& LWS & $H T C$ & $C D$ & $H R C$ & $C R C$ & $C L$ \\
\hline & $(\mathrm{kg})$ & $(\mathrm{kg})$ & $(\%)$ & $(\mathrm{kg})$ & $(\mathrm{kg})$ & $(\%)$ \\
Nellore & 530,75 & 296,94 & 55,96 & 149,69 & 149,44 & 0,27 \\
$\mathrm{~F}_{1}$ Canchim x Nellore & 554,00 & 307,75 & 55,52 & 153,81 & 153,31 & 0,32 \\
$\mathrm{~F}_{1}$ Limousin x Nellore & 556,00 & 311,31 & 55,99 & 155,93 & 155,50 & 0,28 \\
$\mathrm{~F}_{1}$ Aberdeen x Nellore & 591,63 & 332,63 & 56,29 & 166,56 & 166,19 & 0,26 \\
\hline
\end{tabular}

Tabela 5 - Médias do peso vivo ao abate (PVA), peso de carcaça total quente (CTQ), rendimento de carcaça (RC), peso da carcaça direita quente (CDQ) e peso da carcaça direita fria (CDF), em função das dietas

Table 5 - Means of live weight at slaughter (LWS), hot total carcass weight (HTC), carcass dressing (CD), hot right carcass weight (HRC) and cold right carcass weight (CRC), according to the diets

\begin{tabular}{|c|c|c|c|c|c|}
\hline \multirow[t]{4}{*}{$\begin{array}{l}\text { Grupo genético } \\
\text { Genetic group }\end{array}$} & \multicolumn{5}{|c|}{$\begin{array}{l}\text { Parâmetro } \\
\text { Parameter }\end{array}$} \\
\hline & PVA & CTQ & $\mathrm{RC}$ & CDQ & $\mathrm{CDF}$ \\
\hline & $L W S$ & HTC & $C D$ & $H R C$ & $C R C$ \\
\hline & $(\mathrm{kg})$ & $(\mathrm{kg})$ & $(\%)$ & $(\mathrm{kg})$ & $(\mathrm{kg})$ \\
\hline Sem gordura protegida & 548,69 & 307,19 & 55,99 & 154,22 & 153,84 \\
\hline $\begin{array}{l}\text { Without protected fat } \\
\text { Com gordura protegida } \\
\text { With protected fat }\end{array}$ & 567,50 & 317,13 & 55,88 & 158,78 & 158,37 \\
\hline
\end{tabular}

Assim, os grupos mais tardios apresentam carcaças terminadas em maior peso e, conseqüentemente, maior rendimento.

Pode-se afirmar que as perdas por resfriamento da carcaça (Tabela 4$)$ foram mínimas $(0,27 \%)$ e não sofreram efeito da dieta e/ou do grupo genético, corroborando as observações de Koch et al. (1976), que também não relataram efeito do grupo genético sobre estas perdas.

Segundo Koch et al. (1976) e Martins (1997), o percentual de perda no resfriamento revela a ocorrência de fatores, como a perda de umidade e as reações químicas que ocorrem no músculo. Portanto, quanto menor este percentual, maior a probabilidade de a carcaça ter sido manejada e armazenada de maneira adequada.

Ribeiro et al. (2001) relataram perdas por resfriamento de até $3,35 \%$ em carcaças de vitelos com reduzida camada de gordura de cobertura, resultante de dietas com baixo nível de concentrado, e afirmaram que animais apresentando adequada espessura de gordura de cobertura têm suas carcaças mais protegidas contra o ressecamento provocado pelo resfriamento, o que, de certa forma, pode justificar os resultados encontrados no presente estudo, uma vez que as carcaças dos animais experimentais apresentaram excelente grau de acabamento.

Muitos trabalhos avaliando características de carcaças de diferentes grupos de bovinos têm comprovado que animais Bos taurus apresentam maior rendimento de cortes primários (traseiro e ponta de agulha), quando comparados a animais Bos indicus (May et al., 1992). Seria, portanto, provável que a heterose se manifestasse, para esta característica, em mestiços $F_{1}$ destes grupos, como relatado por Gonçalves et al. (1991) e Vaz \& Restle (2001). 
Tabela 6 - Médias do rendimento de cortes primários, em função dos grupos genéticos Table 6 - Average values of prime cuts yield, according to the genetic groups

\begin{tabular}{lccc}
\hline $\begin{array}{l}\text { Grupo genético } \\
\text { Genetic group }\end{array}$ & \multicolumn{3}{c}{$\begin{array}{c}\text { Rendimento (\% da carcaça total) } \\
\text { Yield (\% total carcass) }\end{array}$} \\
\cline { 2 - 4 } & Dianteiro & $\begin{array}{c}\text { Ponta de agulha } \\
\text { Sindquarter }\end{array}$ & $\begin{array}{c}\text { Traseiro especial } \\
\text { Forequarter }\end{array}$ \\
\hline $\mathrm{F}_{1}$ Nellore & $41,00 \mathrm{a}$ & $12,42 \mathrm{~b}$ & $46,58 \mathrm{a}$ \\
$\mathrm{F}_{1}$ Canchim x Nellore & $40,80 \mathrm{ab}$ & $12,70 \mathrm{~b}$ & $46,50 \mathrm{a}$ \\
$\mathrm{F}_{1}$ Limousin Nellore & $39,60 \mathrm{~b}$ & $13,00 \mathrm{~b}$ & $47,40 \mathrm{a}$ \\
$\mathrm{F}_{1}$ Aberdeen x Nellore & $41,65 \mathrm{a}$ & $13,90 \mathrm{a}$ & $44,45 \mathrm{~b}$ \\
\hline
\end{tabular}

Médias seguidas de, pelo menos, uma mesma letra na coluna não diferem entre si, a $5 \%$ de probabilidade, pelo teste Tukey. Means, followed by the same letter, within a column, do not differ, at $5 \%$ of probability, by Tukey test.

Os resultados apresentados (Tabela 6) divergem daqueles obtidos por Prado et al. (2001), em que os cruzamentos de raças européias e zebuínas ( $1 / 2$ Limousin x $1 / 2$ Nelore e $1 / 2$ Canchim x $1 / 2$ Nelore) demonstraram masior eficiência para a produção dos cortes ponta de agulha e traseiro, quando comparados à raça Nelore, e se assemelham, parcialmente, aos achados de Vaz \& Restle (2001), que encontraram maior rendimento de traseiro nos animais puros em contraste à maior porcentagem de ponta de agulha dos mestiços $F_{1}$, como observado para os mestiços $F_{1}$ Aberdeen x Nelore no presente estudo.

Ribeiro et al. (2001) afirmam que seria economicamente desejável maior rendimento do traseiro, uma vez que nele se encontram as partes nobres da carcaça, que alcançam maior valor comercial. Este fato foi observado no presente estudo em relação ao grupo $F_{1}$ Limousin $x$ Nelore, ao contrário do que ocorreu no grupo $F_{1}$ Aberdeen $x$ Nelore.

Vale lembrar a recomendação de Peron (1991) de que certos cuidados devem ser tomados quando se comparam os rendimentos de cortes primários em diferentes animais, pois a divisão de determinados cortes é feita de forma subjetiva, podendo, algumas vezes, levar a resultados distorcidos, como é o caso dos limites dos cortes ponta de agulha e do traseiro especial, que podem variar em função do tamanho do animal, e, caso seus ajustes sejam inadequados, o cálculo dos rendimentos pode ser comprometido.

Quanto aos rendimentos de cortes comerciais do traseiro especial, em função do grupo genético (Tabela 7), observou-se que as menores médias de rendimento de patinho e de coxão duro foram obtidas para o grupo $\mathrm{F}_{1}$ Aberdeen $\mathrm{x}$ Nelore e a maior média de rendimento do corte capa e aba de contra-filé também foi encontrada para este grupo, que, por sua vez, não diferiu dos grupos Nelore e $F_{1}$ Limousin $x$ Nelore.

Não foi observado efeito significativo da interação dieta $\mathrm{x}$ grupo genético para a maioria dos rendimentos de cortes avaliados, exceto para o rendimento do corte músculo $(\mathrm{P}<0,05)$, cujas comparações das médias foram feitas em função dos referidos efeitos conjuntamente (Tabela 8).

As menores médias de rendimento para os cortes músculo (nas duas dietas), patinho e coxão duro, observadas no grupo $\mathrm{F}_{1}$ Aberdeen x Nelore, refletem a tendência do maior rendimento do dianteiro, em detrimento do rendimento total do traseiro, já discutido anteriormente. Por sua vez, as maiores médias de rendimento de músculo no grupo $\mathrm{F}_{1}$ Limousin $\mathrm{x}$ Nelore refletem o maior rendimento do traseiro, em detrimento do rendimento do dianteiro observado para este grupo (Tabela 6), contrariando a afirmação de Berg \& Butterfield (1979) de que, de maneira geral, o animal que apresenta maior rendimento na parte anterior do corpo tende a apresentar, igualmente, maior rendimento da parte posterior, mantendo-se constantes as proporções entre os cortes.

Não foi observado efeito significativo da interação, ou efeitos isolados da dieta e/ou grupo genético, sobre o $\mathrm{pH}$ e a temperatura das carcaças, concordando com Restle et al. (1995), que também não observaram efeito do grupo genético sobre o $\mathrm{pH}$ medido na região lombar, após 24 horas de resfriamento da carcaça de animais de três grupos genéticos (Hereford; $1 / 2$ Jersey $1 / 2$ Hereford, 5/8 Hereford 3/8 Nelore), abatidos aos 14 meses de idade. 
Tabela 7 - Médias do rendimento de cortes comerciais: contra-filé (CF), filé-mignon (FM), coxão mole (CM), alcatra (ALC), lagarto (LAG), patinho (PAT), coxão duro (CD), capa e aba de contra-filé (CAB), em função dos grupos genéticos

Table 7 - Average values of commercial cuts yield, contra-filet (CF), filet (FM), soft round (CM), rump (ALC), shoulder (LAG), thigh round $(C D)$, whole contra-filet $(C A B)$, according to the genetic groups

\begin{tabular}{lcccccccc}
\hline $\begin{array}{l}\text { Grupo genético } \\
\text { Genetic group }\end{array}$ & CF & FM & CM & ALC & LAG & PAT & CD & CAB \\
\hline Nellore & 6,78 & 0,19 & 7,00 & 4,92 & 1,84 & $4,34 \mathrm{a}$ & $4,90 \mathrm{a}$ & $0,64 \mathrm{ab}$ \\
F $_{1}$ Canchim x Nellore & 6,64 & 0,20 & 6,66 & 4,80 & 1,90 & $4,34 \mathrm{a}$ & $4,96 \mathrm{a}$ & $0,55 \mathrm{~b}$ \\
F $_{1}$ Limousin x Nellore & 6,78 & 0,19 & 6,70 & 5,04 & 1,96 & $4,52 \mathrm{a}$ & $4,84 \mathrm{a}$ & $0,60 \mathrm{ab}$ \\
$\mathrm{F}_{1}$ Aberdeen x Nellore & 6,92 & 0,19 & 6,50 & 4,84 & 1,86 & $4,02 \mathrm{~b}$ & $4,52 \mathrm{~b}$ & $0,67 \mathrm{a}$ \\
\hline
\end{tabular}

Médias seguidas de, pelo menos, uma mesma letra na coluna não diferem entre si, a $5 \%$ de probabilidade, pelo teste Tukey. Means, followed by the same letter, within a column, do not differ, at $5 \%$ of probability, by Tukey test.

Tabela 8 - Rendimento do corte músculo, em relação à carcaça total, em função das dietas e dos grupos genéticos Table 8 - Muscle cut yield, in relation to the total carcass, according to the diets and genetic groups

\begin{tabular}{|c|c|c|}
\hline \multirow[t]{2}{*}{$\begin{array}{l}\text { Grupo genético } \\
\text { Genetic group }\end{array}$} & \multicolumn{2}{|c|}{$\begin{array}{c}\text { Dieta } \\
\text { Diet }\end{array}$} \\
\hline & $\begin{array}{c}\text { Sem gordura protegida } \\
\text { Without protected fat }\end{array}$ & $\begin{array}{c}\text { Com gordura protegida } \\
\text { With protected fat }\end{array}$ \\
\hline Nellore & $1,69 \mathrm{aAB}$ & $1,70 \mathrm{aB}$ \\
\hline $\mathrm{F}_{1}$ Canchim $\mathrm{x}$ Nellore & $1,69 \mathrm{aAB}$ & $1,79 \mathrm{aAB}$ \\
\hline $\mathrm{F}_{1}$ Limosin $\mathrm{x}$ Nellore & $1,80 \mathrm{aA}$ & $1,87 \mathrm{aA}$ \\
\hline $\mathrm{F}_{1}$ Aberdeen $\times$ Nellore & $1,63 \mathrm{aB}$ & $1,51 \mathrm{bC}$ \\
\hline
\end{tabular}

Tabela 9 - Médias de temperatura e pH na região do contra-filé e do coxão mole, em função dos grupos genéticos Table 9 - Means of temperature in the contra-filet and soft round regions, according to the genetic groups

\begin{tabular}{lccc}
\hline $\begin{array}{l}\text { Grupo genético } \\
\text { Genetic group }\end{array}$ & \multicolumn{2}{c}{$\begin{array}{c}\text { Temperatura }\left({ }^{\circ} \mathrm{C}\right) \\
\text { Temperature }\end{array}$} & \\
\cline { 2 - 3 } & $\begin{array}{c}\text { Contra-filé } \\
\text { Contra-filet }\end{array}$ & $\begin{array}{c}\text { Coxãomole } \\
\text { Soft round }\end{array}$ & $\begin{array}{c}\text { Contra-filé } \\
\text { Contra-filet }\end{array}$ \\
\hline Nellore & 7,06 & 7,58 & 5,82 \\
$\mathrm{~F}_{1}$ Canchim x Nelore & 6,35 & 7,78 & 5,73 \\
$\mathrm{~F}_{1}$ Limousin x Nelore & 6,63 & 9,00 & 5,69 \\
$\mathrm{~F}_{1}$ Aberdeen x Nelore & 6,83 & 7,50 & 5,67 \\
\hline
\end{tabular}

Os valores médios de $\mathrm{pH}$ para os quatro grupos genéticos (Tabela 9) estão próximos dos valores de $\mathrm{pH}$ final ideal $(5,4$ a 5,5) sugeridos por Bate-Smith (1948), citado por Norman (1978), indicando que a maciez, a suculência e o "saboroma" da carne não foram comprometidos.

Norman (1978) comenta que variações no $\mathrm{pH}$ final da carne e/ou na velocidade em que ele é atingido, com conseqüente alteração de sua capacidade de retenção de água, comprometendo sua qualidade, podem ser observadas em diferentes grupos genéticos. Entretanto, este efeito não foi observado no presente estudo.

Não foi constatado efeito significativo na interação dieta $\mathrm{x}$ grupo genético, para a composição centesimal de músculo, tecido adiposo e osso da carcaça dos animais, bem como para a área de olho de lombo (AOL) e a espessura da gordura de cobertura (EGC), o que possibilitou o estudo dos efeitos isolados, constatando-se efeito da dieta $(\mathrm{P}<0,05)$ apenas para

R. Bras. Zootec., v.33, n.6, p.1876-1887, 2004 (Supl. 1) 
a variável AOL e efeito do grupo genético para as variáveis músculo, tecido adiposo e EGC.

A AOL, medida estimadora de rendimento de cortes da carcaça (Koch et al., 1976), foi maior quando a gordura protegida foi adicionada à ração (Tabela 10), mas não foi observado efeito da dieta sobre estes rendimentos, como discutido anteriormente.

Comparando as médias dos componentes físicos da carcaça dos animais, em função do grupo genético (Tabela 11), houve superioridade do grupo $F_{1}$ Limousin $\mathrm{x}$ Nelore, para o componente músculo, e dos grupos Nelore e $F_{1}$ Aberdeen $x$ Nelore, em relação ao componente tecido adiposo, tendência também observada nas médias de EGC.

Robelin \& Geay (1984) afirmam, com base em dados compilados de diversos autores, que, entre os componentes físicos da carcaça, o mais susceptível a variações da proporção entre as diferentes raças seria a gordura (sobretudo a subcutânea e intramuscular), seguida do componente músculo, enquanto os ossos apresentam variação bem mais discreta. Estes resultados corroboram os obtidos por Galvão et al. (1991), que encontraram maior porcentagem de músculo, menores EGC e menores porcentagens de tecido adiposo nos animais mestiços $\mathrm{F}_{1}$ Nelore $\mathrm{x}$ Limousin, comparados a animais Nelore puros, em estádios equivalentes de maturidade. Concordam também com Bayler et al. (2001), que observaram maior média de EGC para mestiços $\mathrm{F}_{1}$ Nelore $x$ Aberdeen, em relação aos $F_{1}$ Nelore $x$ Canchim. Entretanto, diferem dos resultados obtidos por Peron et al. (1995) e Euclides et al. (1997), que não verificaram efeito do grupo genético sobre as proporções de músculo, gordura e ossos de novilhos Nelore e seus mestiços.

As menores médias de EGC dos cruzamentos $\mathrm{F}_{1}$
Canchim $\mathrm{x}$ Nelore e $\mathrm{F}_{1}$ Limousin $\mathrm{x}$ Nelore, em relação ao grupo Nelore (Tabela 11), divergem dos resultados de Vaz \& Restle (2001), que encontraram diferença significativa entre as médias de EGC dos animais mestiços $\mathrm{F}_{1}$ de cruzas recíprocas entre Nelore e Charolês, em comparação aos animais puros, com significativa heterose (14\%).

Ainda que tenha sido observado efeito do grupo genético sobre a espessura da gordura de cobertura, deve-se ressaltar que os valores médios de EGC, observados para todos os grupos genéticos (Tabela 11), se enquadram na categoria 4 (EGC de 6 a $10 \mathrm{~mm}-$ "gordura uniforme") da escala de 1 a 5, proposta pelo Sistema de Classificação de Carcaças Bovinas e Bubalinas do Ministério da Agricultura do Brasil (Portaria $\mathrm{n}^{\circ} 220$ de 22.09.1981), demonstrando o elevado grau de acabamento de carcaça dos animais no momento do abate. Entretanto, Costa et al. (2002) afirmam que o limite de EGC desejado pelos frigoríficos brasileiros, para que não seja necessária a

Tabela 10 - Médias da área de olho de lombo (AOL) e espessura da gordura de cobertura (EGC), em função das dietas

Table 10 - Means of Longissimus dorsi area (AOL) and back fat thickness (EGC), according to the diets

\begin{tabular}{lll}
\hline Dieta & AOL $\left(\mathrm{cm}^{2}\right)$ & EGC $(\mathrm{mm})$ \\
Diet
\end{tabular}

\begin{tabular}{lll}
\hline Sem gordura protegida & $81,31 \mathrm{~b}$ & $7,46 \mathrm{a}$ \\
$\begin{array}{l}\text { Without protected fat } \\
\text { Com gordura protegida }\end{array}$ & $88,50 \mathrm{a}$ & $8,04 \mathrm{a}$ \\
\begin{tabular}{l} 
With protected fat \\
\hline
\end{tabular} & &
\end{tabular}

Médias seguidas da mesma letra, na coluna, não diferem entre si, a $1 \%$ de probabilidade, pelo teste $\mathrm{F}$.

Means, followed by the same letter, within a column, do not differ, at $1 \%$ of probability, by $F$ test.

Tabela 11 - Médias da composição centesimal de músculo, tecido adiposo e osso da carcaça dos animais, da área de olho de lombo (AOL) e da espessura da gordura de cobertura (EGC), em função dos grupos genéticos

Table 11 - Means of carcass centesimal composition of muscle, fat tissue and bone of animals carcass, Longissimus dorsi area $(A O L)$ and back fat thickness (EGC), according to the genetic groups

\begin{tabular}{lccccc}
\hline $\begin{array}{l}\text { Grupo genético } \\
\text { Genetic group }\end{array}$ & $\begin{array}{c}\text { Músculo (\%) } \\
\text { Muscle }\end{array}$ & $\begin{array}{c}\text { Tecido adiposo (\%) } \\
\text { Fat tissue }\end{array}$ & $\begin{array}{c}\text { Osso (\%) } \\
\text { Bone }\end{array}$ & AOL (cm $\left.{ }^{2}\right)$ & EGC(mm) \\
\hline Nellore & $56,76 \mathrm{c}$ & $28,28 \mathrm{a}$ & 14,95 & 81,50 & $9,29 \mathrm{a}$ \\
F $_{1}$ Canchim x Nellore & $60,49 \mathrm{~b}$ & $24,26 \mathrm{bc}$ & 15,26 & 80,63 & $6,08 \mathrm{~b}$ \\
$\mathrm{~F}_{1}$ Limousin x Nellore & $63,62 \mathrm{a}$ & $21,65 \mathrm{c}$ & 14,73 & 90,00 & $5,99 \mathrm{~b}$ \\
$\mathrm{~F}_{1}$ Aberdeen x Nellore & $58,99 \mathrm{bc}$ & $26,73 \mathrm{ab}$ & 14,28 & 87,50 & $9,63 \mathrm{a}$ \\
\hline
\end{tabular}

Médias seguidas de, pelo menos, uma mesma letra na coluna não diferem entre si, a $5 \%$ de probabilidade, pelo teste Tukey. Means, followed by the same letter, within a column, do not differ, at $5 \%$ of probability, by Tukey test.

R. Bras. Zootec., v.33, n.6, p.1876-1887, 2004 (Supl. 1) 
retirada (corte) do excesso de gordura da carcaça, é de 6,16 mm. No presente estudo, apenas os grupos $\mathrm{F}_{1}$ Limousin $x$ Nelore e $F_{1}$ Canchim x Nelore apresentaram médias de EGC dentro destes limites.

Não foi constatada diferença entre as médias de AOL para os grupos genéticos (Tabela 11), o que está de acordo com os resultados verificados por Lorenzoni (1984), que não observou diferenças entre AOL de animais Nelore, Holandês e mestiços $1 / 2,3 / 4 \mathrm{e}$ $5 / 8$ Holandês x Zebu e de búfalos abatidos com pesos vivos semelhantes.

Também não foi observada alta correlação significativa entre a AOL e a proporção de músculo das carcaças (Tabela 12). Resultados semelhantes foram relatados por Jorge et al. (1997) e estão de acordo com as afirmações de Berg \& Butterfield (1979) e Peron (1991) de que a AOL, tomada isoladamente, apresenta baixa correlação com a proporção de músculo da carcaça.

Koch et al. (1976) relataram alta correlação positiva $(0,93)$ entre a área de olho de lombo e o rendimento de cortes da carcaça, em bovinos de diferentes grupos genéticos (definidos e mestiços).
Segundo esses autores, a análise da regressão destes parâmetros estimou, em média, $2 \mathrm{~kg}$ de rendimento de cortes para cada $\mathrm{cm}^{2}$ de AOL. No presente estudo, a maior média (valor absoluto) de AOL foi observada no grupo $F_{1}$ Limousin x Nelore, que também apresentou maior rendimento do corte traseiro.

Não foi observado efeito significativo da dieta sobre a composição química da seção $\mathrm{HH}$, corroborando a afirmação de Robelin \& Geay (1984) de que a raça parece ter mais influência sobre a composição corporal que o nível nutricional dos animais.

Os teores médios de EE das seções observados para as dietas sem e com gordura protegida foram de 66,53 vs. 65,48\%, respectivamente, discordando da afirmação de Clinquart et al. (1995) de que, em geral, a adição de gordura em dietas de terminação resulta em aumento de 5-15\% no conteúdo de gordura da carcaça. Entretanto, ainda que não tenha sido observado efeito significativo da dieta sobre o teor de extrato etéreo da seção HH, Pires et al. (2002), analisando o perfil de ácidos graxos da carne (contrafilé) dos mesmos animais usados no presente experimento, relataram aumento dos teores de ácidos

Tabela 12 - Correlações entre variáveis relacionadas às características físicas da carcaça dos animais do experimento Table 12 - Correlations among traits related to the physical carcass characteristics of the experimental animals

\begin{tabular}{lcc}
\hline $\begin{array}{l}\text { Variáveis } \\
\text { Traits }\end{array}$ & $\begin{array}{c}\text { Área de olho de lombo } \\
\text { Longissimus dorsi area }\end{array}$ & $\begin{array}{c}\text { Espessura de gordura cutânea } \\
\text { Backfat thickness }\end{array}$ \\
\hline $\begin{array}{l}\text { Músculo } \\
\text { Muscle }\end{array}$ & $0,36 *$ & $-0,66 * *$ \\
$\begin{array}{l}\text { Tecido adiposo } \\
\text { Fat tissue } \\
\text { Osso } \\
\text { Bone }\end{array}$ & $-0,30$ & $0,69 * *$ \\
\end{tabular}

* $(P<0,05) ;{ }^{* *}(P<0,01)$.

Tabela 13 - Médias de extrato etéreo (EE), proteína bruta (PB) e matéria mineral (MM) da seção HH, em função dos grupos genéticos

Table 13 - Means of ether extract (EE), crude protein (CP) and ash of $\mathrm{HH}$ section, according to the genetic groups

\begin{tabular}{lcc}
\hline $\begin{array}{l}\text { Grupo genético } \\
\text { Genetic group }\end{array}$ & & \multicolumn{1}{c}{ Teor médio (\% da MS) } \\
& & Pverage content $(\%$ DM) \\
\cline { 2 - 3 } Nelore & $\mathrm{EE}$ & $22,62 \mathrm{~b}$ \\
$\mathrm{~F}_{1}$ Canchim x Nelore & $68,35 \mathrm{a}$ & $26,10 \mathrm{a}$ \\
$\mathrm{F}_{1}$ Limousin x Nelore & $63,73 \mathrm{c}$ & $27,24 \mathrm{a}$ \\
$\mathrm{F}_{1}$ Aberdeen x Nelore & $63,93 \mathrm{bc}$ & $22,57 \mathrm{~b}$
\end{tabular}

Médias seguidas de, pelo menos, uma mesma letra na coluna não diferem entre si, a $5 \%$ de probabilidade, pelo teste Tukey.

Means, followed by the same letter, within a column, do not differ, at $5 \%$ of probability, by Tukey test.

R. Bras. Zootec., v.33, n.6, p.1876-1887, 2004 (Supl. 1) 
polinsaturados, mais especificamente do ácido linoléico conjugado CLA ( $\left.\mathrm{C}_{18.3} \mathrm{w}-6\right)$ e do ácido linolênico $\left(\mathrm{C}_{18: 3} \mathrm{w}-3\right)$, promovido pela dieta com gordura protegida, o que é bastante desejável, pois tem sido afirmado que o CLA pode conferir à carne e aos seus subprodutos propriedades benéficas à saúde humana (Pariza, 1997; Parodi, 1999; Bessa et al., 2000), além de e o $\mathrm{C}_{18: 3} \mathrm{w}-3$ ter apresentado comprovada influência na prevenção das doenças cardiovasculares (Maloney et al., 2001).

$\mathrm{Na}$ Tabela 13, são apresentados os teores médios de extrato etéreo (EE), proteína bruta $(\mathrm{PB})$ e matéria mineral (MM) das seções $\mathrm{HH}$, em função dos grupos genéticos.

Segundo Robelin \& Geay (1984), a variação da composição química corporal entre as diferentes raças de bovinos envolve, principalmente, o teor de lipídios, sendo observadas maiores porcentagens deste componente nos animais de maturidade mais precoce.

Véras et al. (2000a), avaliando as características de carcaça de animais de maturidades precoce e tardia, recebendo a mesma dieta, relatou que os primeiros tenderam a maiores conteúdos corporais de gordura e menor teor de proteína, o que está supostamente ligado à propensão genética dos mesmos.

Euclides Filho et al. (1997) observaram que animais Nelore, de modo geral, tenderam a apresentar mais gordura na carcaça que seus mestiços com taurinos e, segundo Lana (1991) e Galvão et al. (1991), que também relataram resultados semelhantes, o que aponta maior precocidade fisiológica destes animais em relação aos mestiços.

Vale lembrar que altas porcentagens de extrato etéreo da carcaça tem sido associadas à maior palatabilidade da carne (Costa et al., 2002), que, por sua vez, tem sido relacionada ao marmoreio, que, segundo Robelin \& Geay (1984), é uma das características da carcaça que sofre maior influência do grupo genético, sendo a raça Aberdeen Angus caracterizada como de alto potencial para deposição de gordura intramuscular (Moleta \& Restle, 1996).

Os teores médios de cálcio, fósforo e magnésio da seção $\mathrm{HH}$ foram menores para os grupos de animais que apresentaram maior porcentagem de extrato etéreo na seção (Nelore e $F_{1}$ Aberdeen $x$ Nelore) (Tabela 14).

Véras et al. (2000b) afirma que retenção de minerais depende da composição do ganho e, portanto, pode sofrer efeito do grupo genético. Segundo esse autor, maiores deposições de gordura reduzem as deposições de elementos inorgânicos, uma vez que as concentrações de minerais no tecido adiposo são menores que nos músculos e ossos, o que poderia justificar os resultados observados nesta pesquisa.

Tabela 14 -Teores médios de macro elementos da secção $\mathrm{HH}$, em função dos grupos genéticos Table 14 - Average contents of $\mathrm{HH}$ section macrominerals, according to the genetic groups

\begin{tabular}{lccccc}
\hline $\begin{array}{l}\text { Grupo genético } \\
\text { Genetic group }\end{array}$ & \multicolumn{5}{c}{$\begin{array}{c}\text { Mineral (\% MS) } \\
\text { Mineral (\%DM) }\end{array}$} \\
\cline { 2 - 5 } & $\mathrm{P}$ & $\mathrm{Ca}$ & $\mathrm{Mg}$ & $\mathrm{Na}$ & $\mathrm{K}$ \\
\hline Nellore & $1,32 \mathrm{~b}$ & $2,62 \mathrm{~b}$ & $0,081 \mathrm{~b}$ & $0,236 \mathrm{a}$ & $0,25 \mathrm{a}$ \\
$\mathrm{F}_{1}$ Canchim x Nellore & $1,92 \mathrm{a}$ & $4,10^{\mathrm{a}}$ & $0,113 \mathrm{a}$ & $0,326 \mathrm{a}$ & $0,29 \mathrm{a}$ \\
$\mathrm{F}_{1}$ Limousin x Nellore & $1,54 \mathrm{ab}$ & $3,40 \mathrm{ab}$ & $0,097 \mathrm{ab}$ & $0,290 \mathrm{a}$ & $0,30 \mathrm{a}$ \\
$\mathrm{F}_{1}$ Aberdeen x Nellore & $1,46 \mathrm{ab}$ & $3,14 \mathrm{ab}$ & $0,089 \mathrm{ab}$ & $0,262 \mathrm{a}$ & $0,24 \mathrm{a}$ \\
\hline
\end{tabular}

Médias seguidas de, pelo menos, uma mesma letra na coluna não diferem entre si, a $5 \%$ de probabilidade, pelo teste Tukey. Means, followed by the same letter, within a column, do not differ, at $5 \%$ of probability, by Tukey test. 


\section{Conclusões}

A adição de gordura protegida à dieta dos animais, praticamente, não exerce influência sobre as características de carcaça, promovendo apenas aumento da área de olho de lombo.

O grupo genético influencia a maioria das características de carcaça, com exceção do peso e do rendimento total ao abate.

Animais $\mathrm{F}_{1}$ Limousin $\mathrm{x}$ Nelore revelam superioridade em relação a animais $\mathrm{F}_{1}$ Canchim x Nelore, $\mathrm{F}_{1}$ Aberdeen $x$ Nelore e Nelore puros, quanto ao rendimento de cortes comerciais do traseiro, alta porcentagem de músculo, e baixo teor de gordura de cobertura da carcaça.

\section{Literatura Citada}

ASSOCIATION OF OFFICIAL AGRICULTURAL CHEMISTS - AOAC. Official methods of analysis. 16.ed. Washington, D.C.: 1984. $141 \mathrm{p}$.

ARRUDA, Z.J. A bovinocultura de corte no Brasil e perspectivas para o setor. Campo Grande: EMBRAPA-CNPGC, 1994. 28p. (Documentos, 60).

BAYLER, M.C.A.; CHARDULO, L.A.L.; SILVEIRA, A.C. et al. Características de carcaça e qualidade de carne de novilhos superprecoce de diferentes grupos genéticos e terminados à maturidade. In: CONGRESSO BRASILEIRO DE TECNOLOGIA DE CARNES, 2001, São Pedro. Anais... Campinas: Instituto de Tecnologia de Alimentos, 2001. p.84-85.

BERG, R.T.; BUTTERFIELD, R.M. Nuevos conceptos sobre dessarollo de ganado vacuno. Zaragoza: Acribia, 1979. $297 \mathrm{p}$.

BESSA, R.J.B.; SANTOS-SILVA J.; RIBEIRO J.M.R. et al. Reticulo-rumen biohydrogenation and the enrichment of ruminant edible products with oleic acid conjugated isomers. Livestock Production Science, v.63, p.201-211, 2000.

BURSON, D.E. Quality and yield grades for beef carcasses. North Central Regional Extension Publication 357, Nebraska, 1997. Disponível em <http://www.ianr.unl.edu/pubs/beef >. Acesso em : 23 ago. 2002

CHURCH, D.C. Alimentos y alimentacion del ganado. Corvallis: Oregon State University, 1984.

ClINQUART, A.; MICOL, D.; BRUNDSEAUX, C. et al. Utilisation des matières grasses chez les bovins léngraissement (Utilization of fat concentrates for fattening cattle). INRA Productions Animales, v.8, p.29-42, 1995.

CORRÊA, A.N.S. Análise retrospectiva e tendências da pecuária de corte no Brasil. In: REUNIÃO ANUAL DA SOCIEDADE BRASILEIRA DE ZOOTECNIA, 37., Viçosa, MG, 2000. Anais... Viçosa, MG: Sociedade Brasileira de Zootecnia, 2000. p. 181-206.

COSTA, E.C.; RESTLE, J.; BRONDANI, I.L. et al. Composição física da carcaça, qualidade da carne e conteúdo de colesterol no músculo Longissimus dorsi de novilhos Red Aangus superprecoces, terminados em confinamento e abatidos em diferentes pesos. Revista Brasileira de Zootecnia, v.31, n.1, p.417-428, 2002. (suplemento)
DEMEYER, D.; DOREAU M. Targets and procedures for altering ruminant meat and milk lipids. Proceedings of the Nutrition Society, v.58, p.593-607, 1999.

DUTRA, A.R. Consumo, digestibilidade, desempenho e composição das carcaças de novilhos superprecoces variando a proporção volumoso:concentrado das rações. Viçosa, MG: Universidade Federal de Viçosa, 2000. 214p. Tese (Doutorado em Zootecnia) - Universidade Federal de Viçosa, 2000.

ESTEVES, S.N. Produção de bovinos de corte em manejo intensivo de pastagem. In: SIMPÓSIO SOBRE PRODUÇÃO INTENSIVA DE GADO DE CORTE, 1998, Campinas. Anais... Campinas: Colégio Brasileiro de Nutrição Animal, 1998. p.11-21.

EUCLIDES FILHO, K.; EUCLIDES, V.P.B.; FIGUEIREDO, G.R. et al. Efeito da suplementação com concentrado sobre idades de abate e características de carcaça de bovinos nelore. Revista Brasileira de Zootecnia, v.26, n.6, p.1096-1102, 1997.

galvão et al. (1991)

GONÇALVES, L.C.; SILVA, J.F.C.; VALADARES FILHO, S.C. Composição do ganho em peso de taurinos, zebuínos e seus mestiços e bubalinos. Revista Brasileira de Zootecnia, v.24, n.4, p.413-419, 1991.

HANKINS, O.G.; HOWE, P.E. Estimation of the composition of beef carcasses and cuts. Washington, D.C., 1946. (Tech. Bulletin - USDA, 926).

JENKINS, T.C. Lipid metabolism in the rumen. Journal of Dairy Science, v.76, n.12, p.3851-63, 1993.

JORGE, A.M.; FONTES, C.A.A.; SOARES, J.E. et al. Características quantitativas da carcaça de bovinos e bubalinos, abatidos em diferentes estádios de maturidade. Revista Brasileira de Zootecnia, v.26, n.5, p.1039-1047, 1997.

KOCH, R.M.; DIKEMAN, M.E.; ALLEN, D.M. et al. Characterization of biological types of cattle III. Carcass composition, quality and palatability. Journal of Animal Science, v.43, n.1, p.48-62, 1976.

KOCK, S.W.; PRESTON, R.L. Estimation of bovine carcass composition by the urea dilution technique. Journal of Animal Science, v.48, n.2, p.319-327, 1979.

LANA, R.P. Composição corporal e exigências de energia, proteína e macroelementos minerais ( $\mathrm{Ca}, \mathrm{P}, \mathrm{Mg}, \mathrm{Na}$ e $\mathrm{K}$ ) de novilhos de cinco grupos raciais em confinamento. Viçosa, MG: Universidade Federal de Viçosa, 1991. 134p. Dissertação (Mestrado em Zootecnia) - Universidade Federal de Viçosa, 1991.

LANNA, D.P.D. Fatores condicionantes e predisponentes da puberdade e da idade de abate. Produção de novilho de corte. In: SIMPÓSIO SOBRE PECUÁRIA DE CORTE, 4., 1997, Piracicaba. Anais... Piracicaba: Fundação de Estudos Agrários Luiz de Queiroz, 1997. p.41-78.

LORENZONI, W.R. Estudos sobre eficiência nutritiva e qualidade de carcaça de diversos grupos de bovinos. Viçosa, MG: Universidade Federal de Viçosa, 1984. 51p. Dissertação (Mestrado em Zootecnia) - Universidade Federal de Viçosa, 1984.

MALONEY, A.P.; MONNEY, M.T.; KERRY, J.P. et al. Producing tender and flavoursome beef with enhanced nutritional characteristics. Proceeding Nutrition Society, v.60, p.221-229, 2001.

MAY, S.G.; MIES, W.L.; EDWARDS, J.W. et al. Beef carcass composition of Slaughter cattle differing in frame size, muscle score, and external fatness. Journal of Animal Science, 
v.70, n.6, p.2431-2445, 1992.

MOLLETA, J.L.; RESTLE, J. Influência do grupo genético sobre características qualitativas da carne de novilhos. Revista Brasileira de Zootecnia, v.25, n.5, p.866-875, 1996.

NATIONAL RESEARCH COUNCIL - NRC. Nutrient requirements of beef cattle. 7.ed. Washington, D.C.: 1996. $242 p$.

NORMAN, G.A. pH, carne bovina enegrecida, PSE e encurtamento pelo frio. In: CURSO INTERNACIONAL SOBRE TECNOLOGIA DA CARNE, 1978, São Paulo. Anais... São Paulo: Centro de Tecnologia da Carne, 1978. p.81-86.

PARIZA, M. Conjugated linoleic acid, a newly recognized nutrient. Chemical Industry, v.12, p.464-466, 1997.

PARODI, P.W. Conjugated linoleic acid: an anticarcinogenic fatty acid present in milk fat. Australian Journal of Dairy Technology, v.49, p.93-97, 1999.

PERON, J.A. Características e composição física e química, corporal e da carcaça de bovinos de cinco grupos genéticos, submetidos a alimentação restrita e ad libitum. Viçosa, MG: Universidade Federal de Viçosa, 1991. 126p. Dissertação (Mestrado em Zootecnia) - Universidade Federal de Viçosa, 1991

PERON, A.J.; FONTES, C.A.A.; LANA, R.P. et al. Medidas quantitativas e proporções de músculo, tecido adiposo e ossos na carcaça de novilhos de 5 grupos genéticos submetidos a alimentação restrita e ad libitum. Revista Brasileira de Zootecnia, v.24, n.1, p.126-137, 1995.

PIRES, I.S.C.; OLIVEIRA R.S.; COSTA, N.M.B. et al. Composição centesimal e perfil de ácidos graxos da carne de novilhos precoces alimentados com lipídios protegidos. In: CONGRESSO BRASILEIRO DE NUTRIÇÃO, 17., 2002, Porto Alegre. Anais... Porto Alegre: SBNC, 2002. p.153.

PRADO, C.S.; PÁDU, J.T.; CORRÊA, M.P.C. et al. Avaliação de rendimento e características de carcaça, em bovinos de corte de diferentes grupos genéticos, castrados e inteiros. In: CONGRESSO BRASILEIRO DE TECNOLOGIA DE CARNES, 2001, São Pedro. Anais... Campinas: ITAL, 2001. p.88-89.

RESTLE, J.; VAZ, F.N.; VAZ, R.Z. Qualidade da carcaça e da carne de novilhos de três grupos genéticos abatidos aos quatorze meses de idade. In: REUNIÃO ANUAL DA SOCIEDADE BRASILEIRA DE ZOOTECNIA, 32., 1995, Brasília. Anais... Brasília: Sociedade Brasileira de Zootecnia, 1995. p.647-649

RESTLE, J. Confinamento de terneiros. In: RESTLE, J. (Ed.) Técnicas avançadas na recria e engorda de bovinos de corte. Santa Maria: Universidade Federal de Santa Maria, 1997. 67p.

RIBEIRO, T.R.; PEREIRA, J.C.; OLIVEIRA, M.V.M. et al. Características de carcaça de bezerros holandeses para pro- dução de vitelos recebendo dietas com diferentes níveis de concentrado. Revista Brasileira de Zootecnia, v.30, n.6, p.2154-2162, 2001. (suplemento)

ROBELIN, J.; GEAY, Y. Body composition of cattle as affected by physiological status, breed, sex and diet. In: GLICHRIST, F.M.C.; MACKIE, R.J. (Eds.) Herbage nutrients in the subtropics and tropics. South Africa: 1984. p.525-548.

SILVA, D.J. Análise de alimentos (métodos químicos e biológicos). Viçosa, MG: Universidade Federal de Viçosa, 1998. 165p.

SLANGER, W.D.; MARCHELLO, M.J. DANIELSON, R.B. et al. Muscle tenderness, other carcass traits and the effect of crossbreeding on theses traits in beef cattle. Journal of Animal Science, v.61, n.6, p.1402-1410, 1985.

SNIFFEN, C.J.; O'CONNOR, J.D.; Van SOEST, P.J. et al. A net carbohydrate and protein system for evaluating cattle diets: II carbohydrate and protein avaiability. Journal of Animal Science, v.70, n.11, p.3562-3577, 1992.

UNIVERSIDADE FEDERAL DE VIÇOSA - UFV. SAEG Sistema de análises estatísticas e genéticas. Viçosa, $\mathrm{MG}$, 1999 (Versão 8.X).

VAZ, F.N.; RESTLE, J. Efeito de raça e heterose para características de carcaça de novilhos da primeira geração de cruzamento entre Charolês e Nelore. Revista Brasileira de Zootecnia, v.30, n.2, p.409-416, 2001.

VÉRAS, A.S.C.; VALADARES FILHO, S.C.; COELHO DA SILVA, J.F. et al. Consumo e digestibilidade aparente em bovinos Nelore, não-castrados, alimentados com rações contendo diferentes níveis de concentrado. Revista Brasileira de Zootecnia, v.29, n.6, p.2367-2378, 2000a (Supl. 2).

VÉRAS, A.S.C.; VALADARES FILHO, S.C.; COELHO DA SILVA, J.F. Composição corporal e requisitos energéticos e protéicos de bovinos Nelore, não-castrados, alimentados com rações contendo diferentes níveis de concentrado. Revista Brasileira de Zootecnia, v.29, n.6, p.2379-2389, 2000b (Supl. 2). 